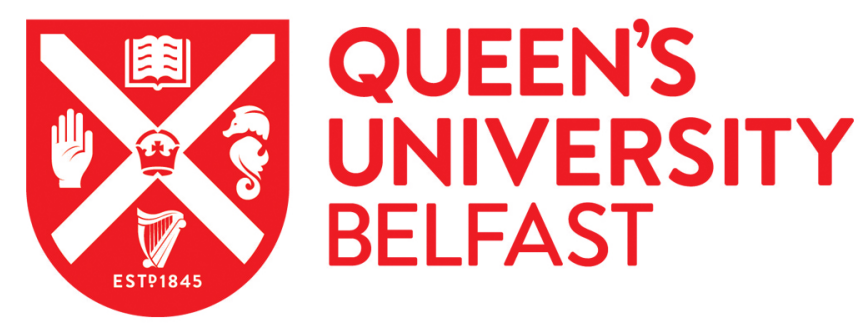

\title{
The Importance of Sexuality Education for Children With and Without Intellectual Disabilities: What Parents Think
}

Stein, S., Kohut, T., \& Dillenburger, K. (2017). The Importance of Sexuality Education for Children With and Without Intellectual Disabilities: What Parents Think. Sexuality and Disability. https://doi.org/10.1007/s11195017-9513-9

Published in:

Sexuality and Disability

Document Version:

Peer reviewed version

Queen's University Belfast - Research Portal:

Link to publication record in Queen's University Belfast Research Portal

Publisher rights

(c) 2017 Springer Science=Business Media, LLLC. This work is made available online in accordance with the publisher's policies. Please refer to any applicable terms of use of the publisher.

\section{General rights}

Copyright for the publications made accessible via the Queen's University Belfast Research Portal is retained by the author(s) and / or other copyright owners and it is a condition of accessing these publications that users recognise and abide by the legal requirements associated with these rights.

Take down policy

The Research Portal is Queen's institutional repository that provides access to Queen's research output. Every effort has been made to ensure that content in the Research Portal does not infringe any person's rights, or applicable UK laws. If you discover content in the Research Portal that you believe breaches copyright or violates any law, please contact openaccess@qub.ac.uk. 


\title{
The importance of sexuality education for children with and without intellectual disabilities: What parents think
}

\author{
Sorah Stein ${ }^{1}$ \\ Partnership for Behavior Change \& \\ Indiana University South Bend, USA \\ $\&$ \\ Karola Dillenburger \\ Centre for Behaviour Analysis, Queen's University Belfast
}

Accepted (2017) in Sexuality and Disability

\begin{abstract}
Individuals with intellectual and developmental disabilities (IDD) experience much higher rates of forced sexual interactions than non-disabled individuals, with incidence ranges from 44\% in children (Briggs, 2006; Kvamm, 2004; van der Put, Asscher, Wissink, \& Stams, 2013) to $83 \%$ in adults (Johnson \& Sigler, 2000). These incidents may be perpetrated by others with disabilities (Langeven \& Curnoe, 2007; van der Put et al., 2013) or, more frequently, by caregivers or others known to the individual (Morano, 2001; Wissink, van Vugt, Mooned, Stams, \& Hendricks, 2015). This may be the case because individuals with intellectual and developmental disabilities (IDD) — especially those with very low IQs — tend to receive little by way of sex education. This study assessed parental beliefs of sexuality education needs of

${ }^{1}$ This paper was written as part of doctoral research by the first author, supervised by the second author. Correspondent author Sorah Stein <steinsorah@yahoo.com>
\end{abstract}


children with and without disabilities through an online survey comprised of questions about the parents, their child, and their attitudes about their child's sexuality. Results showed that parents of children with IDD are less likely to believe their children will have consensual or nonconsensual sex before age 18 than parents of children without IDD, but favor sexuality education for their children, with parents preferring to provide it themselves, with the assistance of or through preparation by workshop with a professional. These finding are discussed in the context of implications for intervention and increasing options for sexuality education for learners with IDD.

Keywords: Sexuality education, Developmental disability, Parent attitudes 


\section{Introduction}

Sexuality education is the process of learning about the physical body and body image, affection and touch, beliefs and values, and gender identities and gender roles. Sexuality education begins at birth when parents bathe, diaper, stroke, hold, and cuddle their baby. It continues as toddlers and preschoolers when parents dress, toilet-train, and teach their child about his or her body. When children begin to have social interactions with peers, and later begin to view and be influenced by the media, they learn about sexuality from their peers and media portrayals of sexual attitudes and behaviors (SIECUS, 2014). For children with intellectual and developmental disabilities, these later childhood interactions and learning opportunities are frequently diminished, as are opportunities for formal sexuality education.

Most formal sexuality education programming falls into one of two categories; abstinence-only, with focus on delaying partnered sex until marriage, and comprehensive sexuality education, which discusses delaying sex until marriage, but also includes information about birth control and safer sex practices to prevent pregnancy and sexually transmitted infections (Kohler, Manhart, \& Lafferty, 2008). Comprehensive sexuality education aims to provide accurate information about all facets of human sexuality, helps develop relationship and other interpersonal skills, and helps learners to develop skills to navigate relationships in ways that are fulfilling and safe (SIECUS, 2014).

Accumulating evidence has suggested that abstinence-only education is not effective in preventing teen pregnancy and sexually transmitted infection (STI) (Carter, 2012; Guttmacher Institute, 2007; Hogben, Chesson, \& Aral, 2010; Kohler, Manhart, \& Lafferty 2008). The US States that employ abstinence-only education report the highest rates of teen pregnancy and births while States providing comprehensive sexuality education report the lowest rates of STIs 
and teen pregnancy (Carter, 2012; Hogben, Chesson, \& Aral, 2010). Comprehensive sexuality education does not only teach about partnered sexual activities (Silverberg, 2009; WalkerHirsch, 2007), it is designed to help people learn who they are and who they will become as unique individuals, including information about how bodies work (Matich-Maroney, Boyle, \& Crocker, 2005) sex roles, assertiveness (Greydanus \& Omar, 2008), and rules of social interactions (Tissot, 2009).

Historically, for individuals with intellectual disabilities, there has been a fear that by providing sexuality education, their sexuality, which, presumably, would have otherwise remained dormant, will somehow be awakened (Lumley \& Scotti, 2001; Walker-Hirsch, 2007). Additionally, for some, there exists a false belief that people with IDD lack sexual interest. This, combined with lack of expertise, often prevents parents and service providers from teaching appropriate sexuality education to individuals with intellectual disabilities (Greydanus \& Omar, 2008; Walker-Hirsch, 2007). The attitudes of parents and staff members about the sexuality of an individual with an intellectual disability tend to determine the amount of education he or she receives (Christian, Stinson, \& Dotson, 2001; Cuskelly \& Gilmore, 2007). Forward-thinking parents and staff are more likely to provide quality sexuality education, while those who are less liberal and believe that providing this education will lead to harm, fail to do so (Scotti, Slack, Bowman, \& Morris, 1996).

In general, within public education settings, people with intellectual disabilities are often excluded from sexuality education (Better Health Channel, 2013; Gowen, Moser, Deschaine, Rowland, Bandurraga, \& Aue, 2011). Unfortunately, this lack of education increases, rather than decreases, their vulnerability to sexual abuse and exploitation (Swango-Wilson, 2009). People with disabilities are up to three times more likely than those without disabilities to be victims of 
physical and sexual abuse and rape, and those with intellectual disabilities are the most vulnerable (WHO/UNFPA, 2009).

Initiating conversations about sexuality and sexual behavior can be difficult for parents of pre-teens and adolescents. Such conversations may be particularly problematic for parents of children with IDD, as sexuality may not be a priority in the face of other time-consuming educational efforts and interventions or may be deferred due to parental reluctance to view their disabled children as sexual beings. Common themes inhibiting parent-child sexuality communications include perceived threat of sexual issues (Ballan, 2012), parents' lack of information (Ballan, 2012; Isler, 2009; Miller et al., 2009; Povilaitienė \& Radzevičienė, 2013), children's inability to understand the information, and children's immaturity (Ballan, 2012; Wilson, et al., 2010).

However, early sexuality education can foster independence and prevent victimization (Ballan, 2012). Pownall, Jahoda, and Hastings (2012) interviewed (in person or by phone) mothers of typically developing children and children with developmental disabilities. The children all had adequate communication skills to discuss sexuality. Results indicated that mothers were somewhat reluctant to initiate conversations about sexuality when their children had developmental disabilities, and, when they did so, it was with less detail than the conversations of mothers with typically developing children.

The primary aim of the current study was to assess parental attitudes to sexuality and sexuality education for children with and without developmental disabilities, including children with and without good communication skills. This is important information for educators who work with learners of all learning abilities and their parents, but especially important when seeking to help overcome barriers to sexuality education for learners with IDD. A secondary goal 
of this study was to determine how parents of children with IDD prefer to access sexuality education information in order to best address their needs with regards to providing this education to their child.

\section{Participants}

Participants were recruited via social media (i.e., Facebook), individual invitation, and email invitation. A total of 71 parents responded to one or more questions posed by the online survey; 9 participants were removed from further analysis due to incomplete data on measures of interest. Of the remaining 62 parents, most were female $(88.71 \% ; n=55)$ and married or living together with their partner $(70.97 \% ; n=44)$. Parental age ranged from 23 to 67 years of age $(M=$ $39.90 S D=9.00)$. With respect to religion, $46.48 \%(n=33)$ of the participants were Christian, $19.72 \%(n=14)$ were Jewish, and 30.99\% $(n=22)$ were atheist or indicated "no religion." Most parents in this survey reported receiving biologically-based $(41.94 \% ; n=26)$ or comprehensive sex education $(30.65 \% ; n=19)$ as youths, with remaining participants reporting "other" $(12.90 \% ; n=8)$, abstinence only $(11.29 \% ; n=7)$, or no $(3.23 \% ; n=2)$ sex education. Thirty parents $(48.39 \%)$ filled out the survey from the perspective of parent of a child with special needs and 32 parents (51.61\%) filled out the survey from the perspective of parent of child who did not have a developmental disability.

\section{Research tool}

The survey tool (access via first author) was developed for this study; some questions were similar to themes in previous studies (Isler, 2009; Povilaitienè \& Radzevičienè, 2013; Wilson, Dalberth, Koo, \& Gard, 2010). The online survey was hosted by Qualtrics (2015) and 
comprised of 31 questions, including forced choice, multiple option, and open-ended responses, that focused on parental beliefs about their child's likelihood of experiencing consensual and non-consensual sex, their child's need for sexuality education, the kinds of sexuality education they prefer for their child, and their preferred means of accessing sexuality education information.

\section{Procedure}

Participants were recruited through an online call for participation, requesting parents of children with and without developmental disabilities, that included the url for the survey. Parents viewed an information page and then clicked "Next" to indicate consent to proceed with the survey. Parents were informed that they could discontinue their participation at any time and that the data they provided would not be identifiable. There was no time to limit to complete the survey. No non-parents responded to the survey.

Institutional Review Board approval for this study was provided by Florida Institute of Technology.

\section{Results}

Most parents $(88.7 \% n=55)$ approved of some form of sexuality education for their child, and the proportion of parents who approved of sexuality education did not vary significantly by the developmental needs status of their child, $\chi^{2}(2)=1.68$, ns. Specifically, $58.1 \%(n=36)$ approved of comprehensive sexuality education; 16.1\% $(n=10)$ approved of "Other" sexuality education; $12.90 \%(n=8)$ approved of biology-based education, $11.3 \%(\mathrm{n}=7)$ did not approve of any sexuality education; and 1.6\% $(\mathrm{n}=1)$ approved of abstinence only 
sexuality education. The ten parents who specified approval of "Other" sexuality education clarified their selection with following open-ended responses: "both comprehensive and biology based," "biology-based with info on contraception and emphasis on abstinence," "will be homeschooled, all questions answered honestly," and "appropriate to his level of comprehension."

Parents who had experience discussing the physiological changes associated with puberty with their children $(n=57)$ were next asked about the types of preparation tools that had been used for such discussions using a check-all-that-apply format. Most parents $(56.14 \% ; n=32)$ selected books; $38.59 \%(n=22)$ selected Internet; $26.32 \%(n=15)$ selected friend; and $21.1 \%(n$ $=12$ ) indicated that they had consulted a professional. Relatively few parents selected relatives $(8.77 \% ; n=5)$, or clergy $(3.51 \% ; n=2)$. Twenty-three parents $(40.35 \%)$ indicated that "Other" tools were relied on, and elaborated on this selection with the following open-ended responses: "combo of above," "spoke with spouse," and many parents replied, "none" or "none yet," indicating their children were very young.

Sixty-two participants responded to the question addressing their child's monthly frequency of masturbation. Of these, 55.17\% $(n=16)$ of parents of children with IDD, versus $75.75 \%(n=25)$ of parents of typically developing children selected "don't know," $31 \%(n=16)$ of parents of children with IDD, versus $27.2 \%(\mathrm{n}=7)$ selected, "my child does not masturbate" and $13.79 \%(n=4)$ of parents of children with IDD versus $.3 \%(n=1)$ of parents of typically developing children selected "this many times per month" and indicated 4-30 times per month as their estimate for monthly frequency of their child's masturbation.

In response to being asked the number of discussions or skills training sessions the parent had with their child specific to properly washing genitals, fifty-seven parents responded with 
open-ended responses including, "every bathtime," "He's only 7 - so I tell him to wash his peepee," "Umm, whenever it seemed needed," "lots he is very sensory aware and wont go near them," "a lot in the beginning and showed her how," and "None - father instructed as part of general showering sequence."

While participants generally understood that many persons with IDD are sexually victimized at some point in their life (range $9 \%-100 \%$; mean estimate $=57.03 \%$ ), only $28.6 \%$ of parents of children with IDD within the present sample believed that their child might have a coercive sexual experience before the age of $18(n=8)$, compared with $44.8 \%$ of 13 parents $(n=$ 13) of parents of typically developing children. Furthermore, parents of children with IDD were significantly less likely to recognize that their child could have a consensual sexual interaction before age 18 than parents of children without disabilities with $28.6 \%$ of parents $(n=8)$ versus $72.4 \%$ of parents $(n=21)$ selecting 'yes.'

Overall, parents believed their child would benefit from sexuality education, with $89.5 \%$ of parents $(n=51)$ in the total sample selecting 'yes', and only $10.5 \%$ of parents $(n=6)$ selecting 'no.' Moreover, despite the low recognition of sexual risk among this group, most parents of children with IDD $(89.3 \% ; n=25)$ acknowledged the utility of sexuality education for their child.

For the question about parental preparedness to discuss sexuality with their child, $84.2 \%$ $(n=48)$ of parents selected 'yes', with only 9 parents $(15.8 \%)$ selecting 'no'. Corroborating this, the top three types of people favored to deliver sex education (57 total respondents) included the participant themselves $(93 \% ; n=53)$, the child's other parent, $(70.2 \% ; n=40)$, or a sexuality educator $(61.4 \% ; n=35)$. For children with special needs, a medical provider was favored to the same extent as child's other parent for parents $(57.1 \% ; n=16)$. 
The three most frequently endorsed resources that parents indicated would be helpful in providing their child with sexuality education included interactive websites $(55.6 \% ; n=30)$, workshop with a professional $(50 \% ; n=28)$, and book with lesson plans $(37 \% ; n=20)$. Parents of children with special needs $(64.3 \% ; n=18)$ were significantly more likely $(\mathrm{p}<.05)$ to endorse workshops with a professional compared to parents of typically developing children $(34.6 \%$; $n=$ 9). Additionally, parents of children with IDD were less likely to endorse interactive websites $(42.9 \% ; n=12)$ than parents of typically developing children $(62.9 \% ; n=18)$. Parents of children with special needs $(42.9 \% ; n=12)$ were more likely to select videos than parents of typically developing children $(23.1 \% ; n=6)$.

Fifty-seven parents responded to the question about the most important thing for their child to know about his/her body. Thirty-three of these parents $(57.9 \%)$ selected 'there is nothing inherently wrong with or defective about his/her body.' Specifically, 50\% $(n=14)$ of parents of children with IDD selected this option, compared to $65.5 \%(n=19)$ of parents of typically developing children. Twenty-eight parents (49.1\%) selected 'personal protection' with 53.6\% ( $n$ $=15)$ of parents of children with IDD compared with $44.8 \%(n=13)$ of parents of typically developing children, with the highest percentage of parents of girls with IDD selecting this response. Twenty parents (35.1\%) selected 'health habits,' with $11(39.3 \%)$ of parents of children with IDD versus 9 (31\%) of typically developing children. Seventeen parents (29.8\%) selected 'privacy skills'; specifically, 10 parents (35.7\%) of children with IDD compared with 7 (24.1\%) parents of typically developing children selected this option. Only 13 parents (22.8\%) selected 'personal pleasure', 8 (28.6\%) were parents of children with IDD including 3 (42.9\%) parents of girls with IDD, compared with 5 (17.2\%) parents of typically developing children. Thirteen $(46.4 \%)$ parents of children with disabilities versus $5(17.2 \%)$ parents of typically 
developing children selected 'proper hygiene,' with $57.1 \%(\mathrm{n}=4)$ of parents of girls with IDD vs. $42.9 \%(n=9)$ of parents of boys with IDD selecting this option.

\section{Discussion}

The present paper reports on an online survey that explored attitudes towards sexuality education among parents of children with intellectual disabilities and parents of typically developing children. Seventy-one parents completed the survey. Overall, most parents were in favour of sexuality education for their child, however, there were some differences in terms of the curriculum to be covered in this educational activity between the two types of parents.

Findings reported here confirm the disparity in parents' perception of risk and actual risk for children and adults with IDD. Various studies report that $25 \%-83 \%$ of individuals with IDD experience some form of sexual abuse (Briggs, 2006; Kvamm, 2004; van der Put, Asscher, Wissink, \& Stams, 2013, Johnson \& Sigler, 2000.) However, only $28.6 \%$ of parents in this survey believe their child with IDD will experience non-consensual sex. Fortunately, over half of the parents of both girls and boys with IDD (57\% and 52.4\%; respectively) identified learning personal protection as important for their child, indicating that this is a significant area of focus for these parents.

Ginevra, Nota, and Stokes (2015) and Holmes and Himle (2014) indicate that lower functioning children with autism spectrum disorders have lower levels of sexuality education and, more importantly, less knowledge about privacy, thus, they are more likely to undress in public, masturbate in public, and engage in inappropriate touch of others. Corona, Fox, Christodulu, and Worloch (2016) report that parents are concerned about their children's knowledge about privacy related to sexual behavior and the rights of others, and state that their 
children touch themselves and others in public. The current survey indicates that $35.7 \%$ of parents of children with IDD want their child to learn privacy skills, confirming that parents are aware of these issues and concerned about the appropriateness of their child's sexual behavior in public contexts.

Pownall et al., (2012) indicate that sexuality education is most valuable as a proactive strategy versus a crisis response. Isler et al. (2009) and Pownall et al. (2012) suggest that parents have primary responsibility for sexuality education and, oftentimes, require support to provide it. Thus, providing parents with the necessary information and tools to support their children with IDD in the area of sexuality education is an important area of intervention for medical providers, mental health professionals, and sexuality educators. 
Ethical approval: All procedures performed in studies involving human participants were in accordance with the ethical standards of the institutional and/or national research committee and with the 1964 Helsinki declaration and its later amendments or comparable ethical standards.

Informed consent: Informed consent was obtained from all individual participants included in the study. 


\section{References}

Ballan, M.S. (2012). Parental perspectives of communication about sexuality in families of children with autism spectrum disorders. Journal of Autism and Developmental Disorders, 42(5), 676-684.

Better Health Channel (2013). Sex education - young people with intellectual disabilities. Retrieved on 04/17/2017 from http://www.betterhealth.vic.gov.au/bhcv2/bhcarticles.nsf/ pages/Sex education- young people with intellectual disabilities

Briggs, F. (2006). Safety issues in the lives of children with learning disabilities. Social Policy Journal of New Zealand, 29, 43-59.

Carter, D. (2012). Comprehensive sex education for teens is more effective than abstinence. $A J N$ The American Journal of Nursing, 112(3), 15.

Christian, L., Stinson, J., \& Dotson, L. A. (2001). Staff values regarding the sexual expression of women with developmental disabilities. Sexuality and Disability, 19(4), 283-291.

Corona, L. L., Fox, S. A., Christodulu, K. V., \& Worlock, J. A. (2016). Providing education on sexuality and relationships to adolescents with Autism Spectrum Disorder and their parents. Sexuality and Disability, 34(2), 199-214.

Ginevra, M. C., Nota, L., \& Stokes, M. A. (2016). The differential effects of Autism and Down's syndrome on sexual behavior. Autism Research, 9(1), 131-140.

Gowen, L. K., Moser, C., Deschaine, M., Rowland, M., Bandurraga, A., Aue, N. (2011). Sexual Health Disparities Among Disenfranchised Youth. Portland State University: Research and Training Center for Pathways to Positive Futures.

Greydanus D. E., Omar H. A. (2008). Sexuality issues and gynecologic care of adolescents with developmental disabilities. Pediatric Clinics of North America, 55(6), 1315-1335. 
Guttmacher Institute (April 18, 2007). Abstinence-Only Programs Do Not Work, New Study Shows. Retrieved on 04/17/2017 from http://www.guttmacher.org/media/inthenews/ $\underline{\text { 2007/04/18/index.html }}$

Hogben, M., Chesson, H., \& Aral, S. O. (2010). Sexuality education policies and sexually transmitted disease rates in the United States of America. International Journal of STD \& AIDS, 21(4), 293-297.

Holmes, L. G., \& Himle, M. B. (2014). Brief report: Parent-child sexuality communication and autism spectrum disorders. Journal of Autism and Developmental Disorders, 44(11), 2964-2970.

Isler, A., Beytut, D., Tas, F., \& Conk, Z. (2009). A study on sexuality with the parents of adolescents with intellectual disability. Sexuality and Disability, 27(4), 229-237.

Johnson, I. M., \& Sigler, R. T. (2000). Forced sexual intercourse among intimates. Journal of Family Violence, 15(1), 95-108.

Kohler, P. K., Manhart, L. E., \& Lafferty, W. E. (2008). Abstinence-only and comprehensive sex education and the initiation of sexual activity and teen pregnancy. Journal of Adolescent Health, 42(4), 344-351.

Kvam, M. H. (2000). Is sexual abuse of children with disabilities disclosed? A retrospective analysis of child disability and the likelihood of sexual abuse among those attending Norwegian hospitals. Child Abuse \& Neglect, 24(8), 1073-1084.

Lumley, V. A., \& Miltenberger, R. G. (1997). Sexual abuse prevention for persons with mental retardation. American journal of mental retardation: AJMR, 101(5), 459-472.

Matich-Maroney, J., Boyle, P. S., \& Crocker, M. M. (2005). The psychosexual assessment \& treatment continuum: A tool for conceptualizing the range of sexuality-related issues and 
support needs of individuals with developmental disabilities. Mental Health Aspects of Developmental Disabilities, 8(3), 77.

Miller, K. S., Fasula, A. M., Dittus, P., Wiegand, R. E., Wyckoff, S. C., \& McNair, L. (2009). Barriers and facilitators to maternal communication with preadolescents about agerelevant sexual topics. AIDS and Behavior, 13(2), 365-374.

Morano, J. P. (2001). Sexual abuse of the mentally retarded patient: Medical and legal analysis for the primary care physician. Primary Care Companion to the Journal of Clinical Psychiatry, 3(3), 126.

Povilaitienė, N., \& Radzevičienė, L. (2013). Sex education of adolescents with mild intellectual disabilities in the educational and social environment: Parents' and teachers' attitude. Special Education, 2, 17-26.

Pownall, J. D., Jahoda, A., \& Hastings, R. P. (2012). Sexuality and sex education of adolescents with intellectual disability: Mothers' attitudes, experiences, and support needs. Intellectual and developmental disabilities, 50(2), 140-154.

Scotti, J. R., Slack, B. S., Bowman, R. A., \& Morris, T. L. (1996). College students attitudes concerning the sexuality of persons with mental retardation: Development of the Perceptions of Sexuality Scale. Sexuality and Disability, 14(4), 248-260.

SIECUS (2014). Fact sheets questions and answers: Sexuality education. Retrieved 12/25/2014 from: http://www.siecus.org

Silverberg C. (2009). What is good sex education?. Retrieved on 04/17/2017 from http://sexuality. about.com/od/seekingsexualhelp/p/sex education.htm

Tissot C. (2009). Establishing a sexual identity: Case studies of learners with autism and learning difficulties. Autism, 13(6), 551-566. 
van der Put, C. E., Asscher, J. J., Wissink, I. B., \& Stams, G. J. J. M. (2014). The relationship between maltreatment victimisation and sexual and violent offending: Differences between adolescent offenders with and without intellectual disability. Journal of Intellectual Disability Research, 58(11), 979-991.

Walker-Hirsch L. (2007). The Facts of Life and More: Sexuality and Intimacy for People with Intellectual Disabilities. Baltimore, MD: Paul H. Brooks.

Wilson, E. K., Dalberth, B. T., Koo, H. P., \& Gard, J. C. (2010). Parents' perspectives on talking to preteenage children about sex. Perspectives on Sexual and Reproductive Health, 42(1), 56-63. 